\title{
Methodology implemented for ore pillar recovery through blasting engineering and explosive technology solutions
}

\author{
J Pavez Orica, Chile \\ E Ríos Orica, Chile \\ S Calderon Orica, Chile \\ F Rucal Orica, Chile
}

\begin{abstract}
A mine operation defined the need to recover 640,000 tons of mineral located between two levels of the mine, distributed between the rib and crown pillars. The sector was located in an area of geological structures and old stopes that due to their condition made it necessary to carry out the recovery in one event. The challenges identified were to blast a large volume of rock while defining a blast sequence so that vibrations did not negatively impact the nearby community or the mine infrastructure. The drilling considered different types of design, depending on the blast areas in the up/down holes, with a total of 46,500 meters. The use of Anfo is usual in mine operations but was discarded because of issues with humidity/water and the need for good fragmentation to assure extraction continuity. Instead bulk emulsions based on Ammonium Nitrate (ANE) were selected and 250 tons of explosive were loaded and distributed over 2,630 explosive decks and 32 days. For precision, flexibility, full programming, 30-second window times, and the multiples decks, the use of electronic detonators (i-kon TM III) and the Blaster3000 system were defined, which have the capacity to work in a programmed, synchronized manner (masterslave), with up to 21,000 electronic detonators of which in this case 4,913 detonators were used. Two points were defined for vibration measurement and control: the first was an underground office area and the second was on the surface. The mass blast was successful at the level of geometry and fragmentation at the base level, allowing continuous extraction (according to weekly plan) for six to seven months. The vibrations in the local community at a distance of 1,500 meters registered a value of $0.75 \mathrm{~mm} / \mathrm{s}$, which according to the USBM \& Goldman Human Perception criterion the level was below the perceptible. It should be noted that this blast is among the 10 largest in the world in terms of volume and the first in number of programmed detonators and initiation in a single event.
\end{abstract}

\section{Introduction}

The Sublevel stoping is a selective mining method applied in vertical or subvertical tabular deposits of great thickness, usually greater than 10 meters. Also, it is possible to apply this method in massive deposits or thick mantles, subdividing the mining into stopes and leaving structural pillars, which later can be recovered in some cases. Both the mineralized rock and the surrounding rock must have good stability conditions to be sufficiently competent or self-supporting.

The pillars aim to keep the local stability of the exploitation units that can be located at the same level (Rib Pillar) or at different levels (crown and sill pillars). 
At an advanced stage of extraction, these pillars may continue to contain an attractive tonnage and grade that can be included in production plans. However, they are subject to unfavorable conditions for conventional recovery methods, and subsequently a single massive technique of blasting is more appropriate to ensure safety and the best economic return.

In this article, the main challenges and Blasting Engineering solutions implemented are shown as a case study to recover 640,000 tons of ore from pillars distributed over an area of 6,500 $\mathrm{m}^{2}$ and at different levels of the mine.

\section{$2 \quad$ Implemented methodology}

The methodology used in the implementation process is shown on Figure 1.

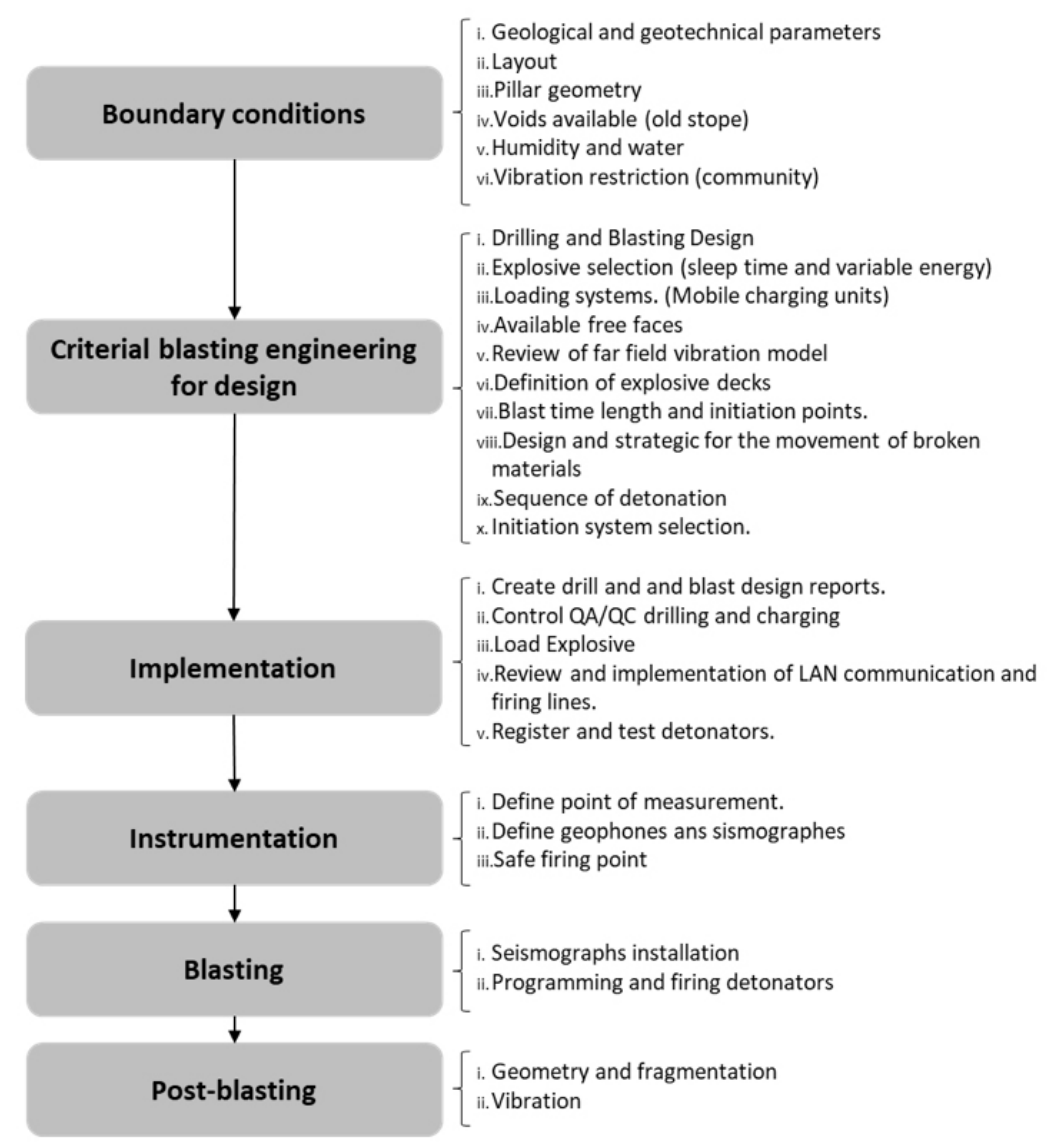

Figure 1 Implemented methodology

The stages considered in the mentioned methodology are described below.

\subsection{Boundary conditions}

Prior to engineering development, current boundary conditions were defined and identified to consider these during the design of the on-site engineering and implementation stages.

\subsubsection{Geological and geotechnical parameters}

Stability and geomechanical conditions influence the way a sector is recovered and define the possibility of blasting in various events (with conventional explosives) or in a massive way, which implies greater technology to ensure the result. 

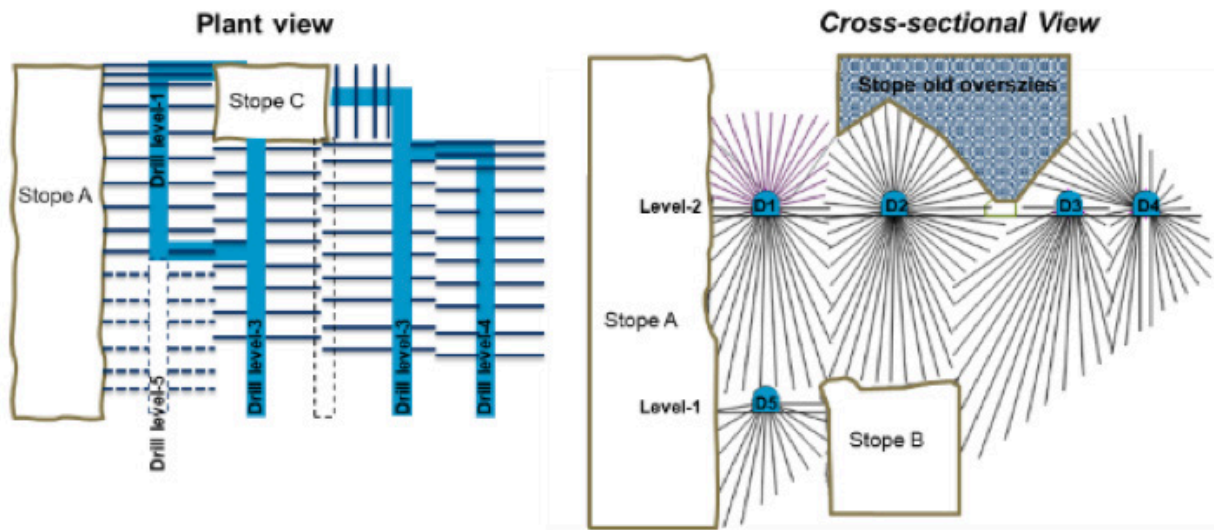

Figure 2 Schematic view of the blasting sector

Given the condition of the existing cavities and the structural condition, for this case a massive scale event (one event only) was decided upon to minimize the risk of loss of area and to maximize the possibility of recovering more mineral.

\subsubsection{Layout}

The drill levels for recovery of pillars depend on the layout of production and transport levels of the old ore body extraction. It is not always possible to recover all the areas without the construction of new drill levels to reach the entire volume to be broken.

For the case study, the old production and extraction levels were used: levels one and two. Drill drift one (D1), two (D2), three (D3) and four (D4) are in Level Two, and drill drift five (D5) is in Level One.

\section{Cross-sectional View}

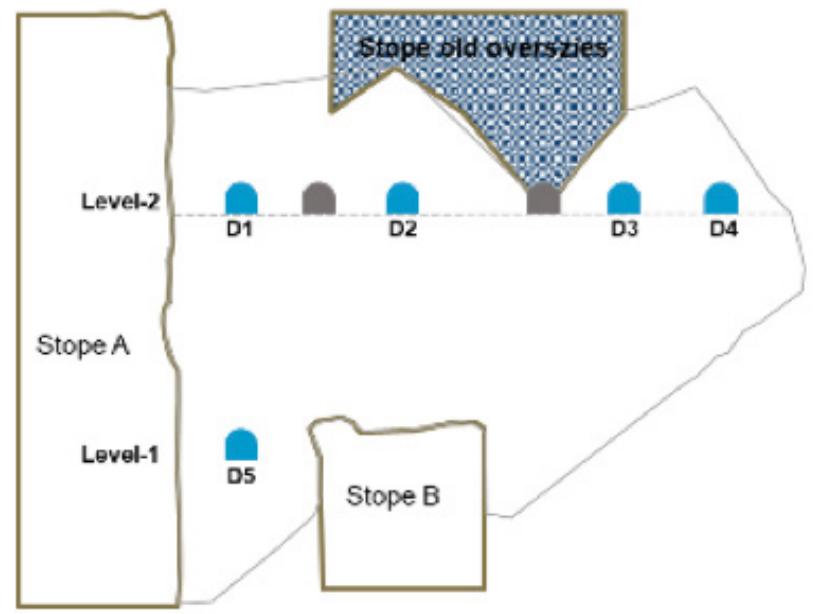

\section{Figure 3 Layout blasting sector}

\subsubsection{Pillar geometry}

- The sector of ore to recover has three pillars, as shown in Figure 4.

- The rib pillar is located between stope $A$ and $B$, with dimensions 60 meters (length) $\times 25$ meter (width) $\times 80$ meters (height).

- The crown pillar is located over Level Two and is an old extraction level. Its dimensions are 40 meters (length) $\times 70$ meter (width) $\times 23$ meters (height) .

- The sill pillars are located under the crown pillar of Level Two. The dimensions are 40 meters (length) $\times 50$ meters (width) $\times 50$ meters (height) . 


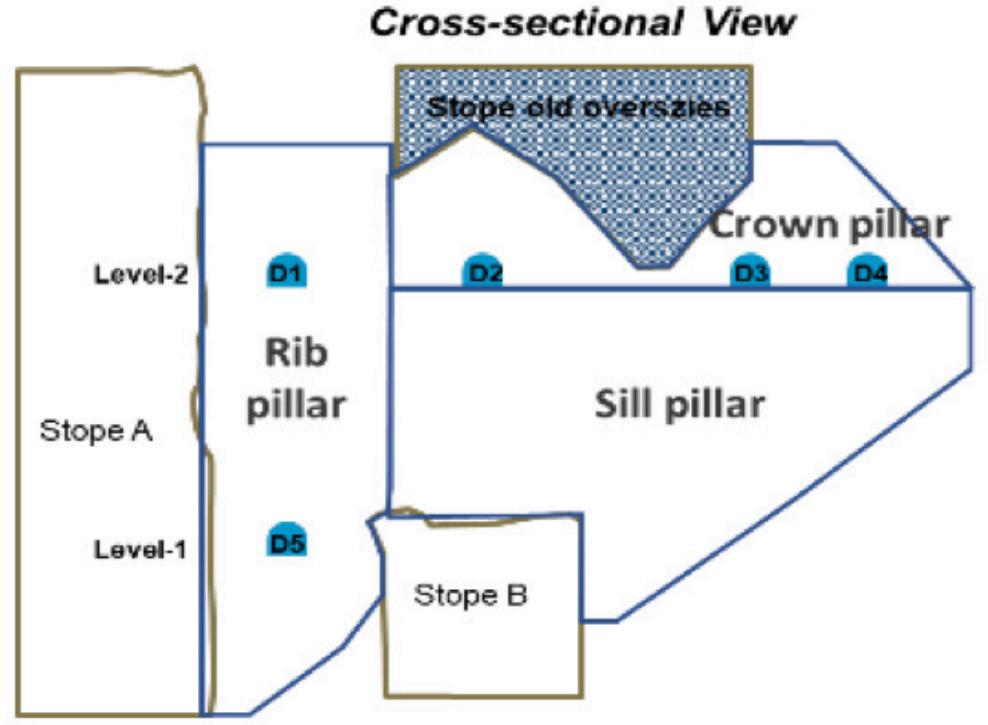

Figure 4 Pillars geometry

\subsubsection{Voids Available (old stopes)}

The blast to recover the support pillars of the sector considers available voids and geometries from old stopes previously exploited, as shown in Figure 5.

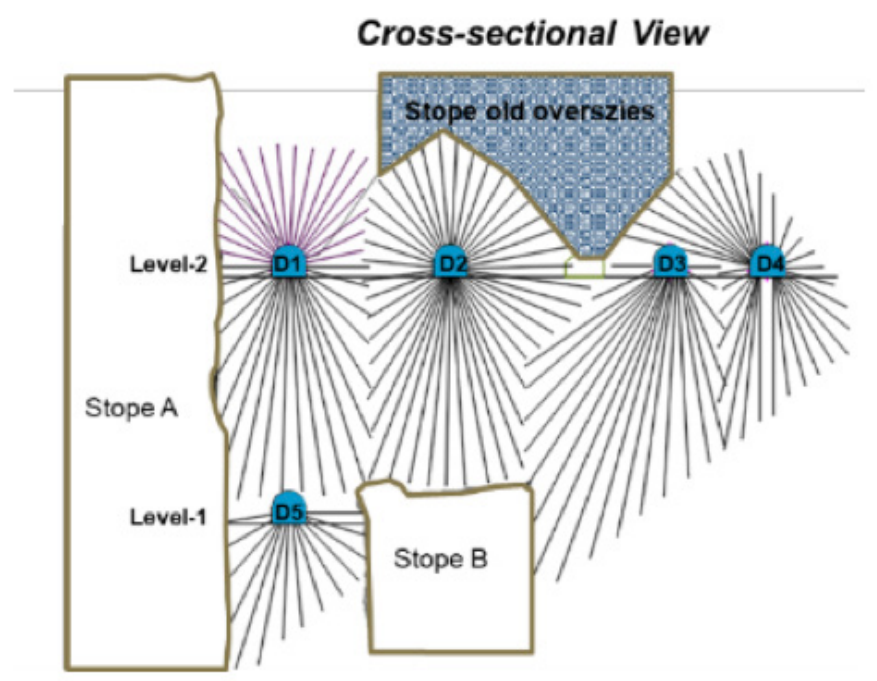

\section{Figure 5 Cross-sectional view of the blast}

The Cavity Monitoring System (CMS) was used to measure the old stopes, and the voids available have the following conditions:

a) Stope $A$ has an available void of 1,200,000 tons; it would receive $40 \%$ of total material blasted;

b) Stope B has an available void of 285,000 tons;

c) Stope $C$ has an available void of 80,000 tons associated with the previous opening.

Stope B and Stope C would receive $60 \%$ of total material blasted.

The crown pillar is an old extraction level, which presents remnant material from the previous exploitation. An appropriate sequence to minimize the premature entry of this oversize material reducing the risk of freezing the blasting had to be considered. 


\subsubsection{Humidity and water}

The conditions of humidity and water for this blast are associated with the down hole drilling that does not break into the voids (stope).

Sixty percent of drilling was down hole; however, $80 \%$ did not break into the cavity thus allowing water to accumulate, which then affected the explosives selected.

\subsubsection{Vibration restriction (community)}

The mass blast was located at a distance between 1,500 to 2,000 meters from the local community. The customer had defined the following criteria to control and minimize the impacts for the blasting:

a) Minimize the blast time;

b) Achieve the USB \& Goldman for human perception.

To evaluate the impact of the blasting on the community, the use of the USBM \& Goldman (USA-1948) Human Response to Vibration criteria was established. This criterion establishes that the human response is a function of the frequency and the maximum amplitude of the vibration, and can be classified as: perceptible, annoying or intolerable, as shown in Figure 6.

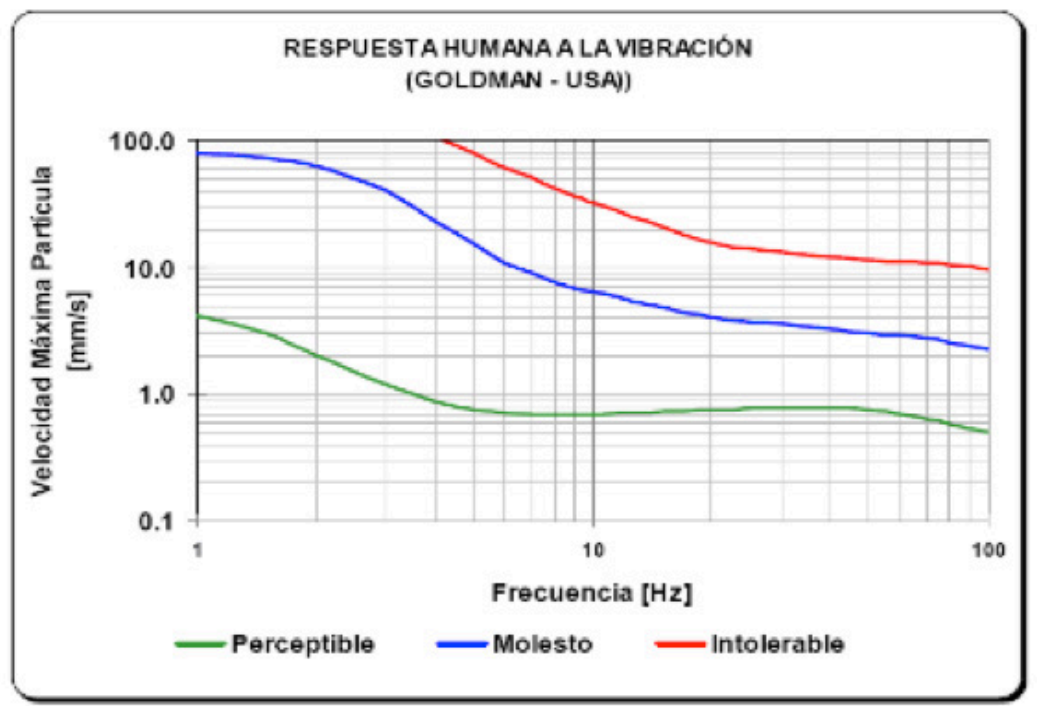

Figure 6 USBM \& Goldman Human Response to Vibration

\subsection{Criteria blasting engineering for design}

The criteria applied are described below.

\subsubsection{Drilling and Blasting Design}

The drilling design was submitted by the customer and reviewed for Orica Technical teams. It considered the accumulated experience of the mine and the boundary conditions described in point 2.1.

The diameters available are 3.0, 3.5 and 4.5 inches, for up-hole, radial and long-hole drilling respectively. This was distributed in the follow detail:

a) Diameter 3.0 inches was applied on rib pillars for up-drilled holes from D1 and D5 drifts;

b) Diameter 3.5 inches was applied on crown and sill pillars (central sector) for radial drilled holes from the D2 drift, and also on the rib pillar for radial drilled holes from D4 drift. This sector was confined without free face; we then designed auxiliary radial holes to generate dynamics free faces; 
c) Diameter 4.5 inches was applied on sill and rib pillars for down-drilled holes from D1, D3 and D5 drifts. The longer holes were drilled from D3 drift up to 50 meters down.
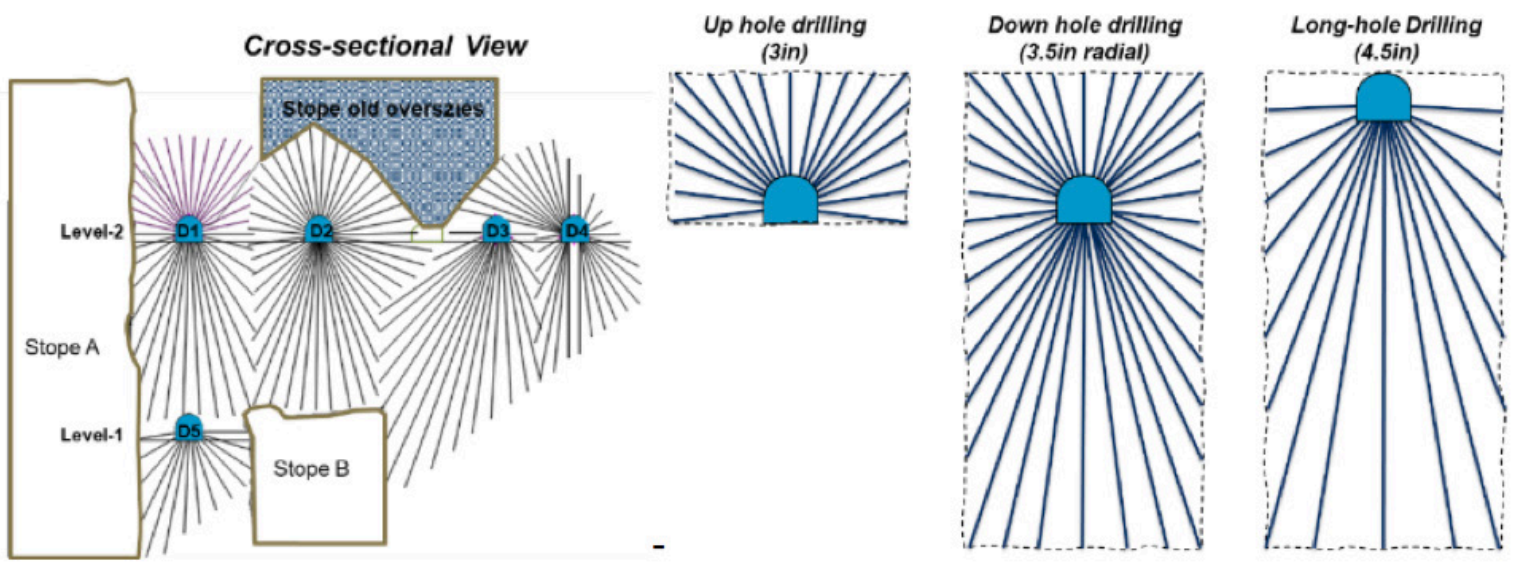

Figure 7 Drilling design for mass blast

The actual drilling patterns used in the mine are described in Table 1.

Table 1 Drilling pattern description

\begin{tabular}{|c|c|c|c|c|}
\hline $\begin{array}{c}\text { Diameter } \\
\text { (inches) }\end{array}$ & Drilling Type & $\begin{array}{c}\text { Burden } \\
\text { (meters) }\end{array}$ & $\begin{array}{c}\text { Toe spacing } \\
\text { (meters) }\end{array}$ & $\begin{array}{c}\text { Drilling Length } \\
\text { (meters) }\end{array}$ \\
\hline 3.0 & Up hole & 2.0 & $2.6-3.0$ & Up to 25 \\
\hline 3.5 & Radial & 2.5 & $2.8-3.3$ & Up to 35 \\
\hline $\mathbf{4 . 5}$ & Down long-hole & 3.3 & $3.0-3.8$ & Up to 50 \\
\hline
\end{tabular}

For the massive blast, energy modeling was conducted using JKSimblast software. This modeling allowed a homogeneous energy distribution to be visualized in the rock volume to be broken. Through this visualization, zones with low energy (oversize potential) or high energy (damage to explosive column nearby) concentration were identified to modify the explosive charge design, as shown in figure 8 .

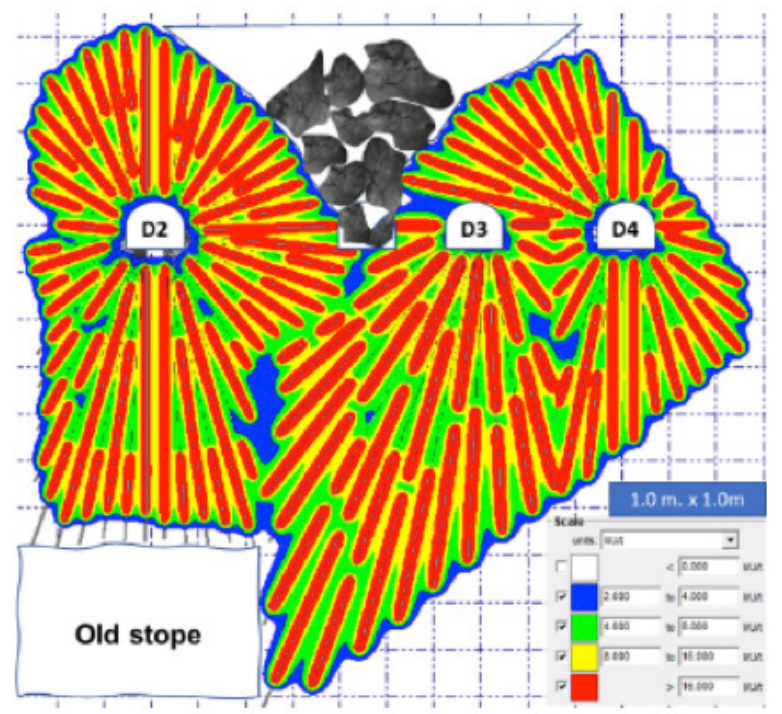

Figure 8 Production energy distribution

\subsubsection{Explosive selection (sleep time and variable energy)}

The explosive sleep time and resistance to water are essential when selecting an explosive especially for this blast type in which the explosive loading operation is extensive (close to 30 or more days). 
The humidity and water within boreholes or because of geological structures affect the explosive type to be used, especially when considering the sleep time of the explosive. Therefore, in this case the use of ANFO was not viable due to its null resistance to humidity and water. Products such as bulk or packaged emulsions were considered.

The bulk emulsions based on Ammonium Nitrate (ANE) contain two liquid phases that are immiscible with each other, one of which is dispersed as small drops (dispersed phase) within the other (continuous phase), in addition to substances (emulsifiers) to improve their stability. These emulsions are sensitized in the hole by chemical agents or solid elements. The bulk emulsions used in underground mining, due to their manufacture, are not affected by water, and thus are feasible alternatives for downdraft loads with drainage problems. On the other hand, given their viscosity, they allow greater adherence to the walls of the perforations, achieving loads in diameters of up to 4.5 inches and 50 meters in length. Operationally, they improve waste management (i.e. no bags or boxes are used to contain them), and control of loaded columns. In addition, the use of bulk emulsion allows mechanization of loading, which reduces manual handling of materials, labor hours, and human exposure during blasthole loading.

The use of packaged emulsions has the disadvantage of requiring more work and manual handling with more opportunities for injuries, transport exposure and temporary storage and environmental impact from solid waste generation (boxes).

Given the conditions and variables, the use of Bulk emulsion for up hole Subtek ${ }^{\mathrm{TM}}$ Velcro and for down hole Subtek ${ }^{\mathrm{TM}}$ Charge was chosen. Also, packaged emulsion was used (3.5 inches $\times 16$ inches) in down hole and specific blast sectors. From an on-site adjustment, the total amount of explosive was 140 tons, $80 \%$ of which was bulk emulsion, and the continuous loading process required 32 days.

The Subtek ANETM Orica is a base emulsion that is stored in the tanks of the MCU (Mobile Charger Unit) and in the front face a chemical agent is added that is mixed in the blasthole to manufacture Subtek ${ }^{\mathrm{TM}}$ Velcro or Charge. Subtek ${ }^{\mathrm{TM}}$ Velcro has special adhesion properties that allow loading in up holes, and Subtek ${ }^{\mathrm{TM}}$ Charge emulsion is a product that allows loading in horizontal and down holes. In both products, according to the needs it is possible to achieve a variable density to manufacturing specifications in the MCU.

Table 2 Subtek specifications

\begin{tabular}{|c|c|c|}
\hline Parameters & Subtek $^{\mathrm{TM}}$ Velcro & Subtek $^{\text {TM }}$ Charge \\
\hline Density (g/cc) & $0.94-1.20$ & $0.90-1.20$ \\
\hline VOD (m/s) & $>3,000$ & $>3,000$ \\
\hline Hole Type & Dry, Wet or Dewatered & Dry, Wet or Dewatered \\
\hline Hole direction & Up hole & Tunnels, Down hole \\
\hline Sleep time (1) & 21 days & 21 days \\
\hline
\end{tabular}

Note: (1) The technical specialist was consulted for more days.

\subsubsection{Loading systems. (Mobile charging units)}

The mechanized explosive loading allows productivity and work safety to be improved, in addition to improving environmental aspects regarding waste treatment in comparison to other methods. 


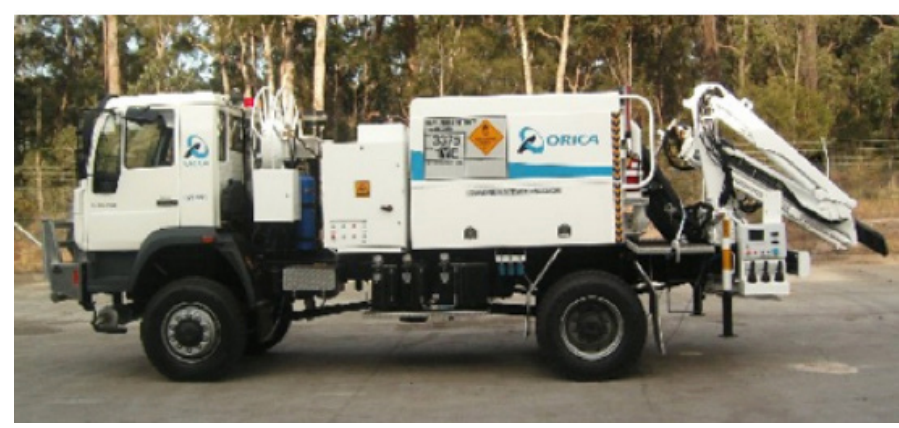

Figure 9 Mobile charging units. (MCU)

The bulk emulsion was delivered in iso-tanks with a capacity of 25 tons. Close to seven iso-tanks were needed for the blast.

The explosive loading operation used two Mobile charge units (MCU). These MCUs have a tank with a four-tonne capacity for emulsion base (Subtek ${ }^{\mathrm{TM}}$ ANE), and three tanks for the gasifying solution.

The MCUs have a robotic arm system for loading up hole and another pulley system for loading down hole.

\subsubsection{Available free faces}

The recovery of pillars usually uses old stopes (voids) and available drifts. The design of drill and blast (timing sequences) considers the movement of broken material into voids and uses available drifts for drilling and loading explosives.

In addition during the blasting process, dynamic free faces were designed, using timing sequences.

For the case study, the generation of the initial free faces did not consider mechanized systems and additional drifts.

For the ribs pillars, inclined and vertical drilling was used, and the movement of the broken material was designed in blast lateral direction, as shown in Figure 10, into stopes A and B. In Level One, for (D4) the blast was designed for lateral movement of broken material.

\section{Plant view}

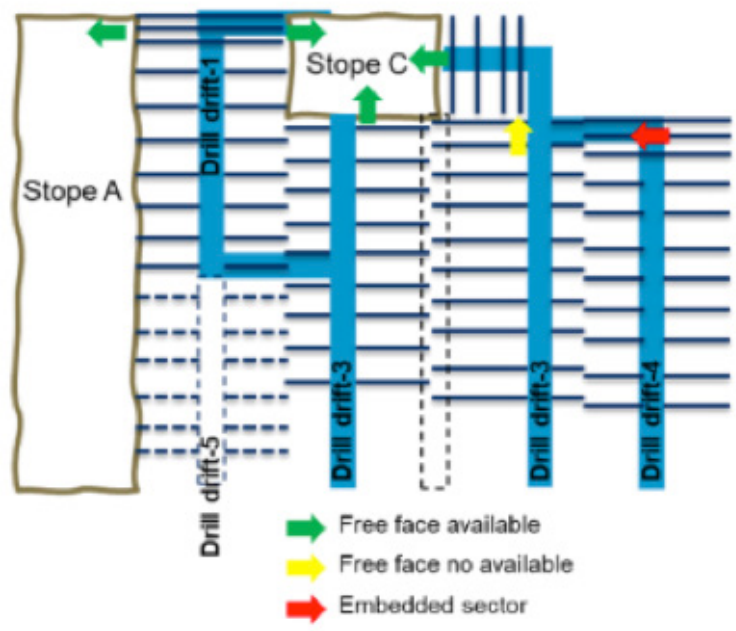

Figure 10 Free face distribution plant

As seen in Figure 11 the down hole of the sill pillar was drilled parallel to the free face of the stope, allowing the broken material to move into the stope. 

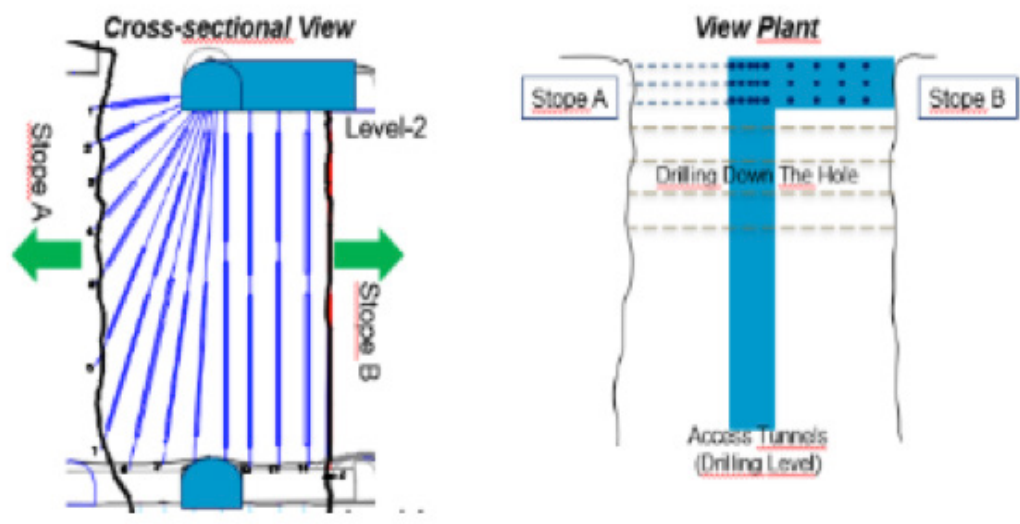

Figure 11 Free face Ribs Pillars (Slot type)

For the crown pillar (b), design of radial up-hole drilling did not have a free face in front then (b) was blasted to (a) after that, as seen in Figure 12 (b).

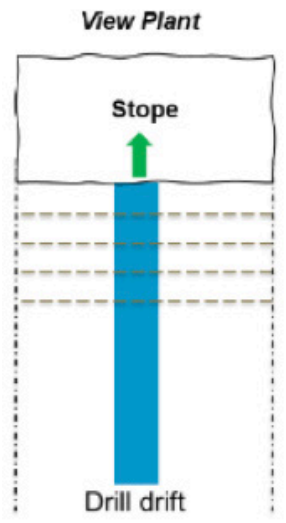

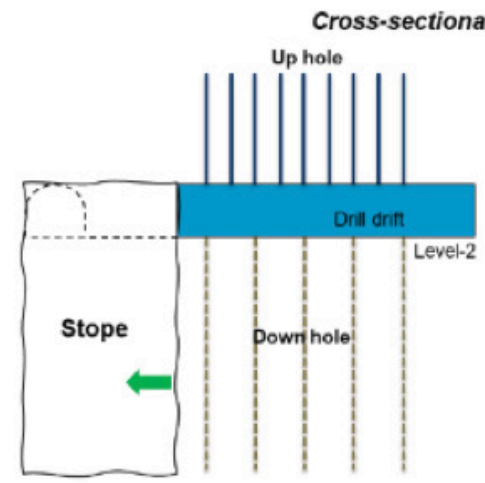

(a)

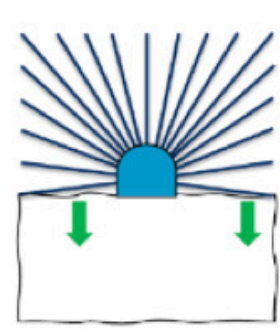

(b)

Figure 12 Free face sill (a) and crown (b) pillars

\subsubsection{Review of far field vibration model}

Together with the client a far field vibration Devine model using historical information of the sector of the blast was generated. Figure 13 shows the vibration model used, with a correlation of $88 \%$ ( $K=410$ and $\alpha=-1.268$ ).

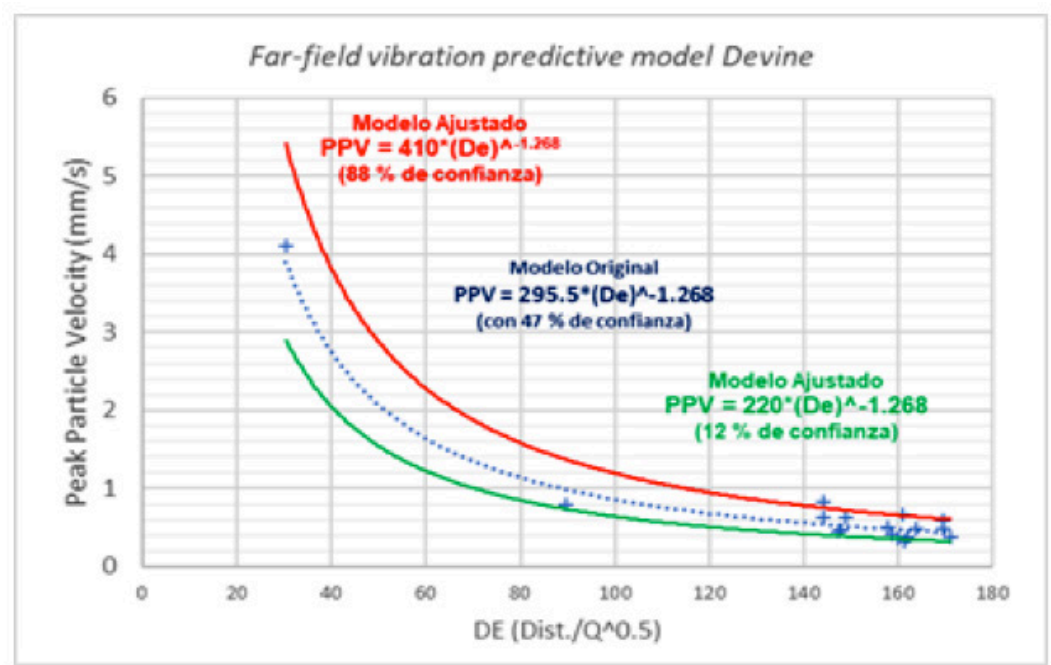

Figure 13 Far-field Devine Model 
According to the model in Figure 13, for a maximum charge per delay of 300 kilograms, and in a distance range between 1,500 to 2,000 meters, the estimate of the particle velocity would fluctuate between 1.1 to $1.5 \mathrm{~mm} / \mathrm{s}$, as shown in Table 3.

Table 3 Vibration estimation according to charge per delay and distance

\begin{tabular}{|c|c|c|c|c|}
\hline \multirow{2}{*}{$\begin{array}{c}\text { Distance } \\
\text { (m.) }\end{array}$} & \multicolumn{4}{|c|}{ Charge per delay (kg.) } \\
\cline { 2 - 5 } & 300 & 400 & 500 & 600 \\
\cline { 2 - 5 } & \multicolumn{4}{|c|}{ Estimated PPV (mm/s) } \\
\hline 200 & 18.4 & 22.1 & 25.5 & 28.6 \\
\hline 500 & 5.8 & 6.9 & 8.0 & 9.0 \\
\hline 1000 & 2.4 & 2.9 & 3.3 & 3.7 \\
\hline 1500 & 1.4 & 1.7 & 2.0 & 2.2 \\
\hline 2000 & 1.0 & 1.2 & 1.4 & 1.5 \\
\hline
\end{tabular}

\subsubsection{Definition of explosive decks (weight and length)}

The length of the explosive column (or "deck") depended on the charges per delay and an adequate energy distribution of the drill pattern designed.

The charge per delay is a function of the restriction of vibrations into the nearby communities and far field vibration modeling. This was calculated using the far field vibration predictive model considering the point of interest as shown in Figure 14.

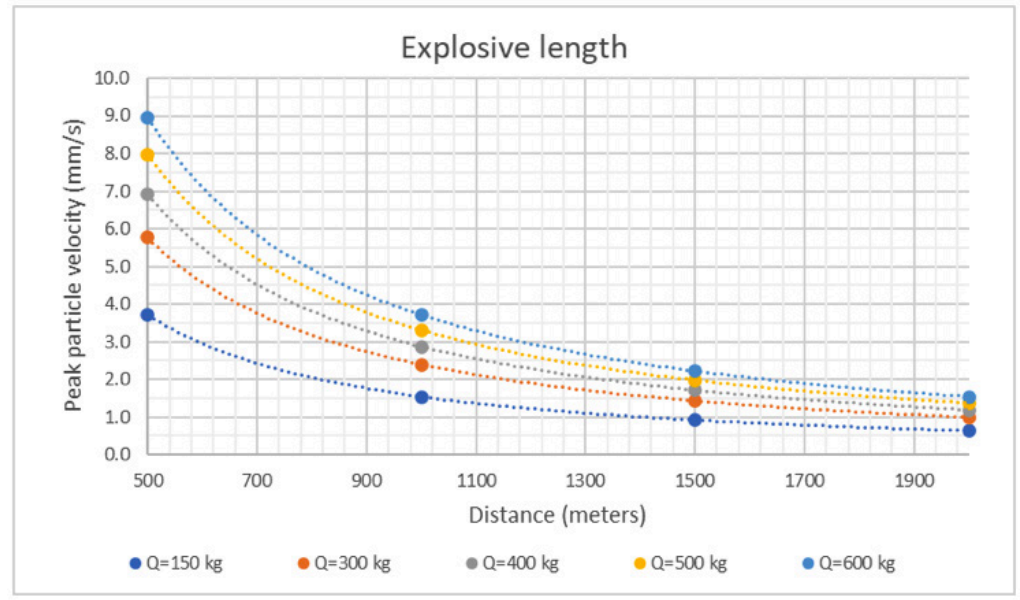

Figure 14 Estimation of the explosive charge (or decks)

According to Goldman's Human Response criteria, to minimize the impact to the community at 1,500 meters, a maximum vibration of $1.5 \mathrm{~mm} / \mathrm{s}$ is recommended, so the maximum charge per delay should be between 150 to 300 kilograms.

Table 4 shows the weight and deck length for the diameter used. As shown, the charge per delay for a production blast fluctuates between 150-200 kilograms.

Table 4 Weight and deck length

\begin{tabular}{|c|c|c|c|c|c|c|}
\hline \multirow{2}{*}{$\begin{array}{c}\text { Diameter } \\
\text { (inches) }\end{array}$} & $\begin{array}{c}\text { Kilograms of } \\
\text { explosive per meter } \\
\text { (density = 1.1 g/cc) }\end{array}$ & \multicolumn{4}{|c|}{ Weight (kg) and decks length (m) vs diameter } \\
\cline { 5 - 8 } & 150 & 300 & 400 & 500 & 600 \\
\hline 3.0 & 5.0 & 30 & 60 & 80 & 100 & 200 \\
\hline 3.5 & 6.8 & 22 & 44 & 59 & 73 & 67 \\
\hline $\mathbf{4 . 5}$ & 11.3 & 13 & 27 & 35 & 44 & 22 \\
\hline
\end{tabular}


According to the established criteria, as shown in Figure 15, 2,585 decks were designed and distributed in the follow way:

a) The average charge per delay was the $130 \mathrm{~kg}$;

b) $97 \%(1,735$ deck $)$ of the decks were under the established restriction;

c) $3 \%$ (52 deck) of the explosive charges were between 300 and $580 \mathrm{~kg}$.

In case (c) a larger charge per delay was permitted because the explosive columns or deck were separated by more than $15 \mathrm{~m}$, minimizing the effect of overlapping of stress waves in the point of interest.

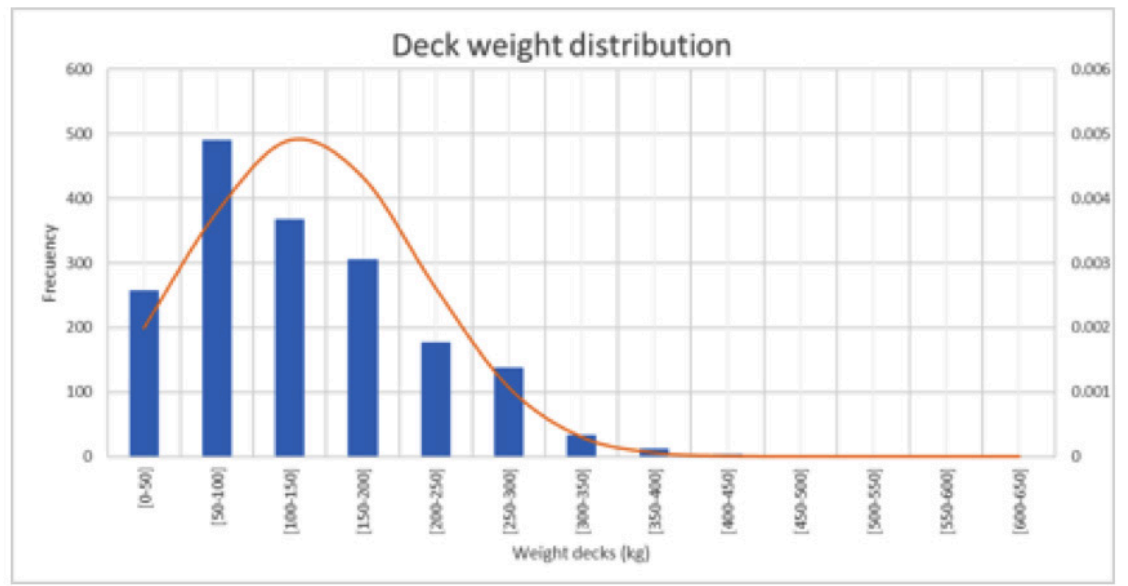

Figure 15 Weight distribution decks

\subsubsection{Blast time length and initiation points}

The blast time length depends on community restriction, number of decks, rows and interactions between blasts. Figure 16 shows the interaction between the sectors, from one to five, both in the vertical and in the horizontal. Then for the case study, the length of the blast was designed to be a total of 26 seconds.
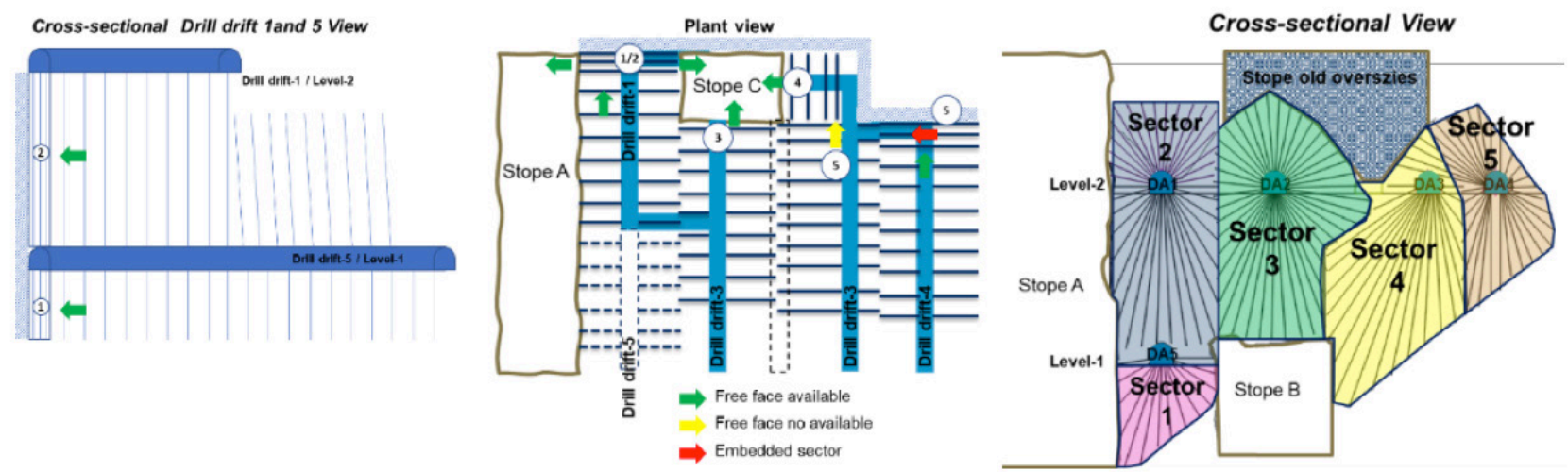

Figure 16 Blast time length and initiation points

\subsubsection{Design and strategy for the movement of broken materials}

The strategy to define the movement of the broken material (volumes) into the stopes considered the following criteria:

a) Maximize the use of old stope A volume;

b) Create the new dynamic free faces for an effective blasting of the blind or embedded areas by sequences. This was the case of the roof (in rib pillar and crown pillar) and sector D4;

c) Ensure effective movement of the ore broken, programing the sector sequentially into dynamic free faces; 
d) Minimize the risk of damage to the explosive charging due to displacement of wedges, using minimum times between the blasted sectors;

e) Reduce the risk of loss of available void due to the premature entry of coarse material from old stopes located above, mainly for the sector two, three and four.
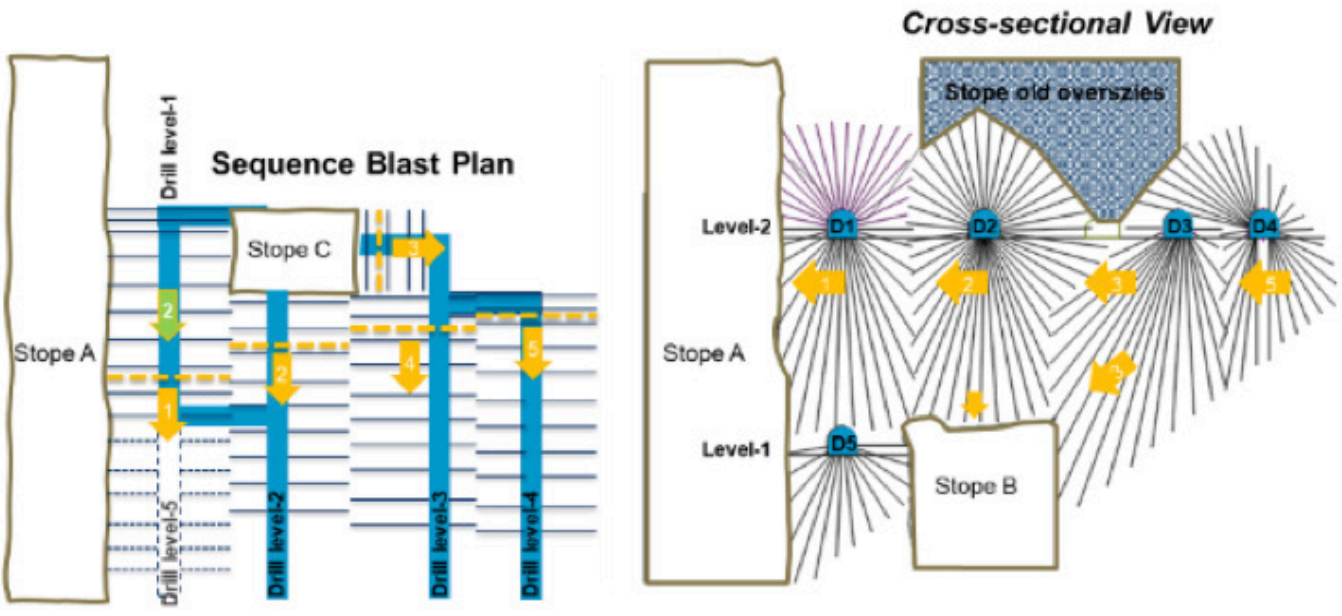

\section{Figure 17 Sequence Blast Plan Case Study}

For the mass blast, the blast design strategy considered the following:

a) Move the highest percentage of material to stope A. It was estimated that $90 \%$ of the rib pillar (vertical) material would be directed to stope A. The other $10 \%$ of material, due to the effect of gravity, would be moved to stope B;

b) For combined drilling levels, down hole drilling (free face) would have a gap of two to three rows (four to five meters) regarding the stopes with up hole drilling that do not have a free face (blind area);

c) Minimize the risk of wedge displacement in the blasting sectors by defining simultaneous fronts with a minimum gap between them. The minimum gap should not exceed the three rows of down hole drilling (approximately nine to ten meters) and the up hole drilling should be set back regarding the lower level to two rows at the minimum (four to five meters) in order to ensure effective movement;

d) Minimize the waiting time of sectors, which have presence of material in the stopes above that would reduce the void available;

e) Ensure the effective use of the free faces generated for embedded sectors or without free face.

f) Stope A would receive 39\% of the blasting and the remaining $61 \%$ should be received by stope $\mathrm{B}$, for a swelling of 391,000 tons. The sequence and strategy should dictate the direction of the flow and movement of the broken ore.

\subsubsection{Sequence of detonation}

Based on the experience in the mine, a delay of 25 milliseconds between decks was defined and established.

Due to the distribution and large number of charges, in 34\% of the cases the time difference between charges was reduced to 1 millisecond. But these charges were located at different levels and distances, reducing the risk of wave coupling in the near field as shown in Figure 17.

In addition to the previous considerations, the sequence was simulated using the Orica SHOTPlus ${ }^{\mathrm{TM}}$ Underground software as shown in Figure 18. 


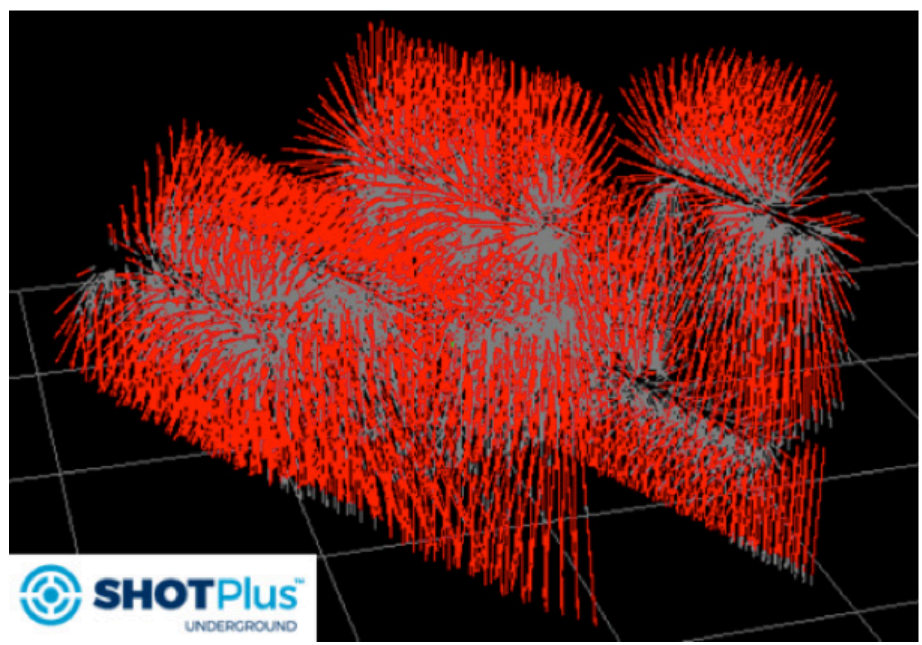

Figure 18 Design 3D blasting using SHOTPlus UGTM Orica

SHOTPlus TM UG permitted the visualization and simulation of the mass blast, and the results of the cavity monitoring system (CMS) of old stopes.

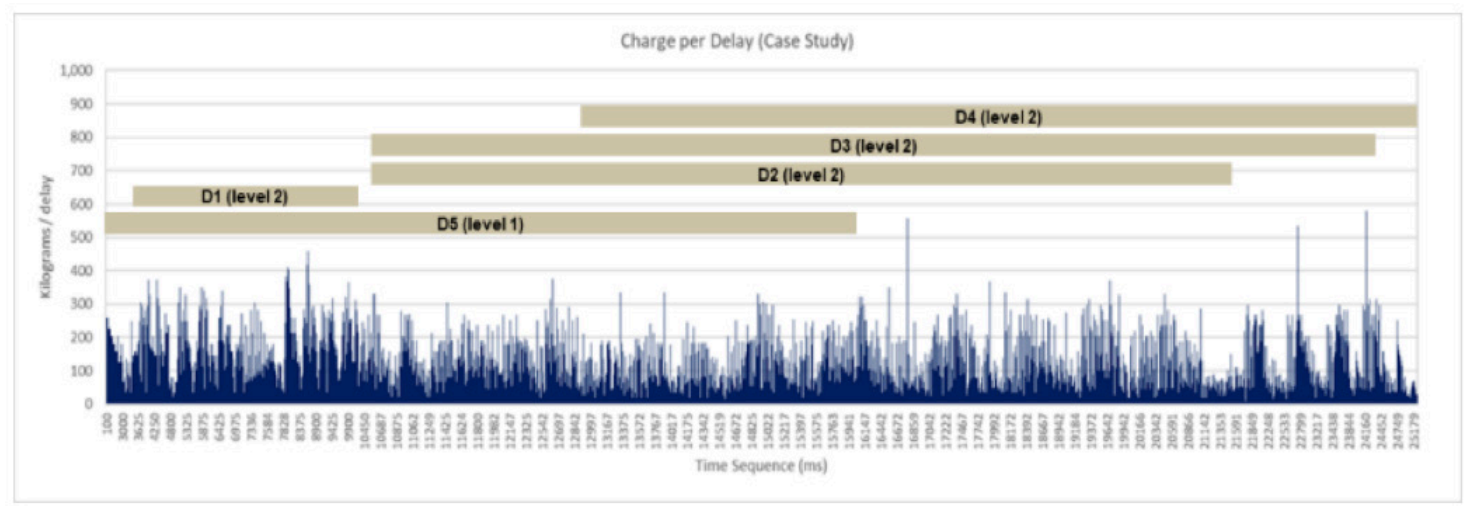

Figure 19 Charge per delay and timing sequence

\subsubsection{Initiation system selection}

The initiation system selection for the mass blast depends on the number of decks, blast time length, precision, flexibility, full testing, programming and reliability.

For this type of blast, non-electric detonators have greater technical disadvantages, given that:

a) They have a limited availability of delays (times), thus generating an increase in the charge per delay and length of the sequence;

b) They have greater dispersion, increasing the risk of overlapping;

c) There is a greater probability of cut-off to generate possible misfire and safety risk;

d) These are not tested before the blast.

The electronic detonators i-kon ${ }^{\mathrm{TM}}$ III Orica comply with challenges for this mass blast because they have the following characteristics:

a) Greater sequence flexibility, allowing full programming with intervals of 1 millisecond;

b) Larger time window, allowing sequences of up to 30,000 milliseconds;

c) Higher precision by having $0.001 \%$ of scatter;

d) Tested conditions of detonators before and during the loading process of the explosive, minimizing 
post-blast events. In extensive loading blasts (greater than 20 days), the system allows the status of the detonators to be verified by means of communication tests and current leakage;

e) Elimination of the use of detonating cord and composite guides (safety wicks);

f) Availability to centralize the initiation of blasting. The safety of the blasting personnel makes it necessary to start the blast from a safe position, centralizing the detonation of the multiple explosive columns located at different sectors and levels;

g) Master slave increment of capacity detonators programming and firing up to 21,000 units.

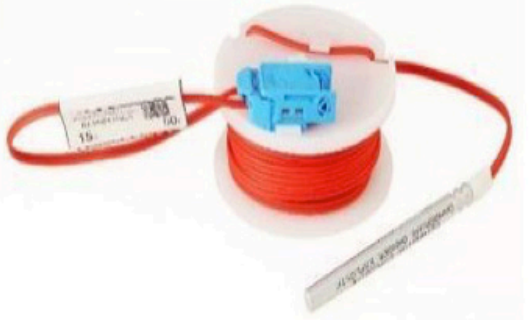

(a) Detonator I-kon ${ }^{T M}$ III

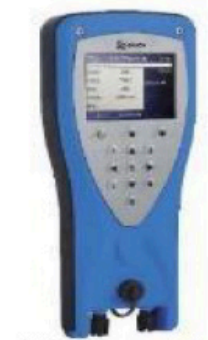

(b) Logger ${ }^{\mathrm{rm}}$ II

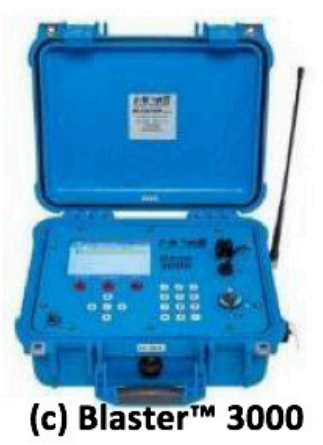

Figure 20 Electronic blasting system i-kon ${ }^{\mathrm{TM}}$ III Orica

The i-kon TM III detonator (see figure 20a) is designed to be used in electronic blasting, and its characteristics are the following:
a) Establishes bidirectional communication with the Logger.
b) Has a unique identification (ID) code assigned at the factory.
c) Can be programmed from 0 to 30,000 milliseconds
d) Has high accuracy of delays $0.005 \%$.
e) Can only be started and registered by i-kon TM III equipment.

The Logger TM II (see figure 20b) is the recording equipment for the i-kon TM III detonators, and its characteristics are the following:

a) Inherently Safe Recording Equipment.

b) Capacity of 500 detonators per logger simplifies mooring and allows larger blasts.

c) Flexibility to change registration route in the field and control changes

d) Stronger verification signal reduces blast delays due to communication problems from electrical interference, leaks, constantly displaying on screen.

e) Faster programming time of approx. 5 minutes (500 detonators per logger).

f) Support for multiple languages, delivers USB downloads and larger memory capacity.

The Blaster 3000 (in follow B3000) is the control unit for the blasting process (see Figure 20c), and its characteristics are:

a) Each team allows the initiation of 3,000 detonators. In synchronized mode, seven B3000s can be connected, totaling 21,000 detonators;

b) It has a communication mode via LTE, WIFI, LAN, Leaky Feeder (LF) and legwire;

c) It can fire in simultaneous or sequential mode up to 7 production and / or different development blast located at levels;

d) It can be started remotely from any point in the mine using a repeater if necessary; 
e) Equipment has a unique encrypted key that comes from the remote box that is installed near the blast in a safe place;

f) To start the process, the key is placed in the remote box to later enter another master key, allowing the detonators to be programmed;

g) Blast reports can be extracted from Loggers remotely after firing;

h) It contains a geophone that allows the output of the blasting to be confirmed, delivering the vibration graph on the screen immediately after the blast.

For the mass blast 2,544 decks and a blast time length of 26 seconds, requiring 4,913 electronics detonators. This required the use of 21 Logger TM II and five Blaster3000 units. The configuration of use of the B3000 considered one device as the master controller to initiate the blast, one remote device and three slave devices, as shown in Figure 21. Communication was planned via LAN but with back up wire.

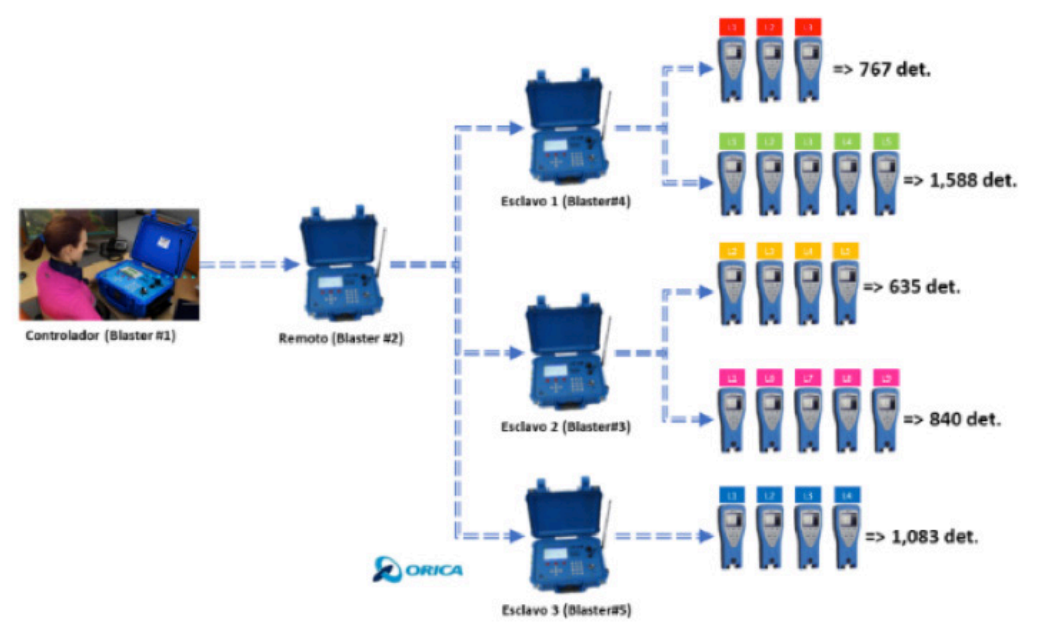

Figure 21 Blasting equipment configuration scheme

\subsection{Implementation}

The implementation points for the mass blast are described below.

\subsubsection{Drill and blast design reports}

The theoretical design was reviewed and modified together with the customer to consider the actual drilling conditions. In order to keep the energy distribution homogenous in the volume rock or blasting timing t, only bottom decks were adjusted. Also, this review allowed the visualization of potential areas with risk of poor geometry or generation of oversize.

\subsubsection{QA/QC drilling / charging}

The implemented operational controls are described below:

a) Daily controlling of the output of products from the explosives magazine to the specific work sectors, making a daily count of what was delivered and loaded;

b) Recording the amount of explosive and detonators loaded in each borehole;

c) Reconciling explosives on a daily and weekly basis and at the end of each loaded sector. The magazine keeper, loading supervisor and blasting engineer were responsible of this operation;

d) Closing each loaded area to prevent the entry of people. 


\subsubsection{Loading explosive}

For the blast, two mobile explosive loading vehicles were used. The loading operating order considered, retreating from each drift (D1, D2, D3, D4), as shown in Figure 22.

In addition, a safety restriction in drill drift 1 and 5, was established not to perform parallel work.
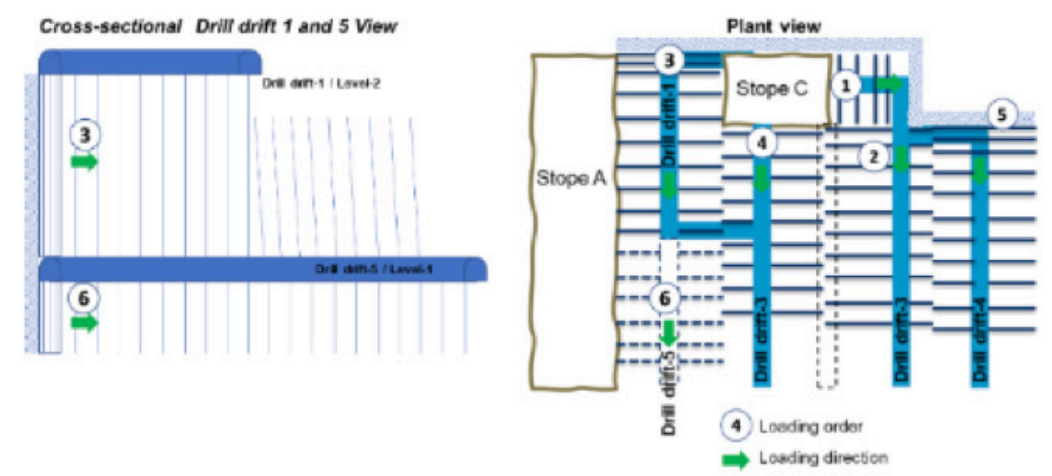

Figure 22 Explosive loading sequence with MCU

For the loading operation of the blast, risk controls were considered to minimize the loss and/or movement of explosives in the column:

a) in up hole drilling self-inflated bags were used;

b) at the bottom of the blasthole, bags with sand were used in holes broken to create stopes or present the risk of losing the bottom prematurely to nearby stopes (overbreak). The bags were tied with $6 \mathrm{~mm}$ thick strings to bolts installed in the wall of drift.

\subsubsection{Review and implementation of LAN communication and firing lines}

Days prior to the blasting, the LAN points enabled by the customer for blasting were tested. Also, a plan was generated to use legwire as a backup in case of failure of the LAN points in the mine.

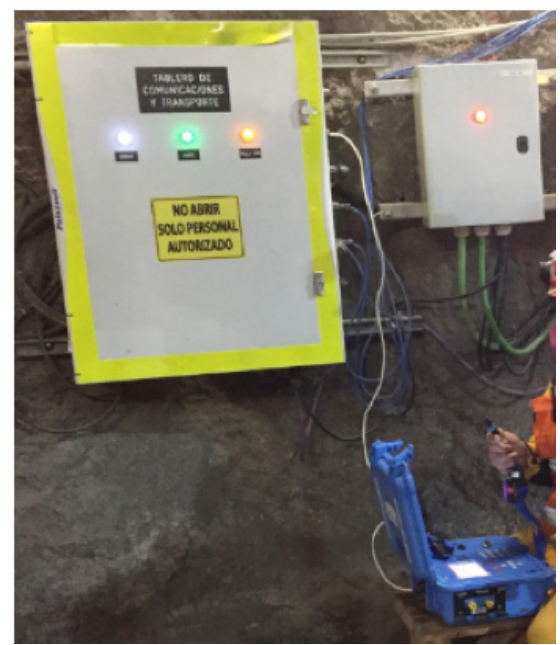

Figure 23 Review of LAN communications

\subsubsection{Registering and testing detonators. (controls)}

During the recording process of the 4,913 detonators, 21 Logger Ils and five Blaster 3000s were used. Each Logger II and Blaster3000 had the color codes that identified it for each of the drill drifts. The color code is shown in Figure 24. 


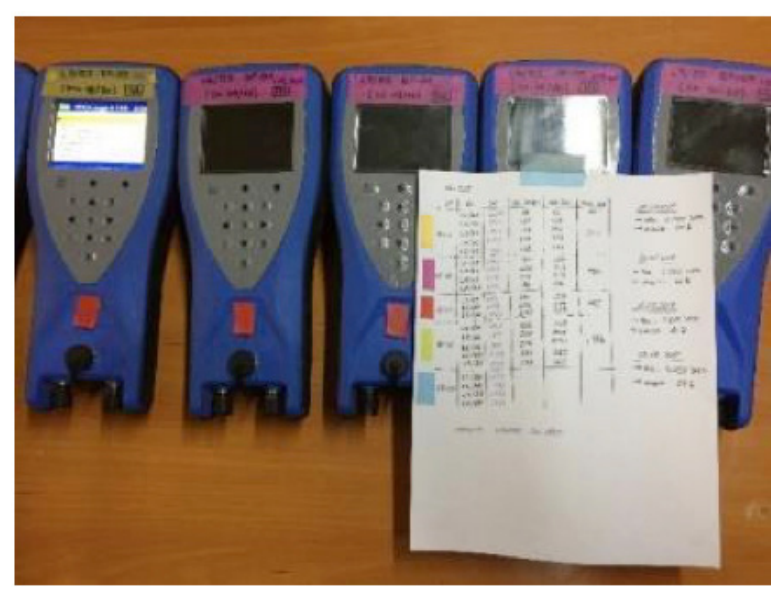

Figure 24 Identification Logger ${ }^{\mathrm{TM}}$ II by color code

The communication and current leakage of the detonators was tested for status. The information was compiled in a report from each drift and each day's work, which was then communicated to customer and technical teams.

At the end of each drift and before leaving, communication and current leakage were reviewed to detect any anomaly that should be solved. Each drift without anomaly was closed for the entry of any personnel, and a report of the number of registered detonators was delivered to the customer for review with detonators delivered from explosives storage.

\section{$2.4 \quad$ Instrumentation}

\subsubsection{Define points of measurement}

Two points of measurement were defined in the underground mine and one on the surface close to the community. These points were the following:

- Point One (P1) at 250 meters from the blast in level two of the sector of blast;

- Point Two (P2) at 2,000 meters from the blast in the underground mine;

- Point Three (P3) at 1,500 meters of the blast in the nearby community.

\subsubsection{Define geophone and seismographs}

For the blast, geophones and equipment of far field were used for the measurement points inside the underground mine.

The client used other equipment on the surface, close to community.

\subsubsection{Safe firing point}

The safe firing point was defined at a distance over 1,000 meters and out of line of the airblast. For the blast, a plan B with legwire was used in case of an electrical problem.

\subsection{Blasting}

\subsubsection{Seismograph installation}

All geophones were installed the same day of the blast. The geophones used in the underground mine were installed on a concrete floor using a bolt drilled into the floor. 
The geophone of the measurement point P1 (Figure 25) was located close to the Logger II and Blaster3000 equipment. The geophone of the measurement point P2 was located close to the offices of the underground mine.

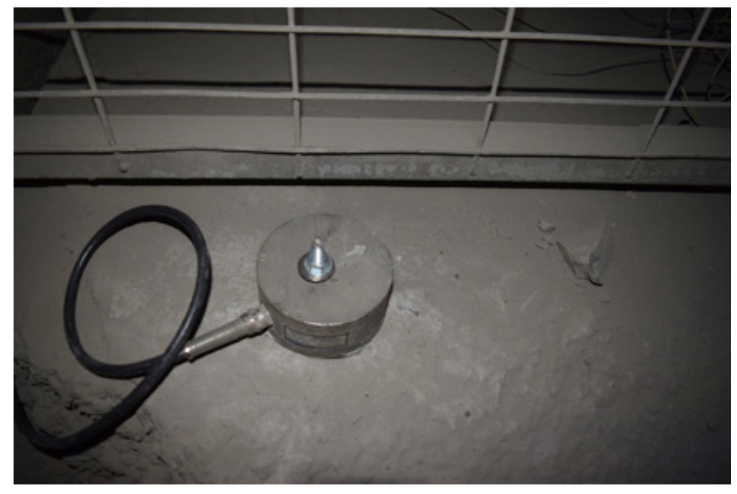

Figure 25 Geophones far field in underground mine. (P1)

\subsubsection{Programming and firing detonators}

The Logger II and Blaster3000 blasting equipment were located near measurement point P1 at 200 meters away from the sector of the blast.

From the sectors loaded with explosives (D1 to D5), lines from the drifts to the position of the Loggerlls of each drift according to the color codes were extended.

The Loggers II were serially connected to each B3000, according to the color codes, as shown in Figure 26. This was defined to allow easy viewing during the communication and leakage current review processes, before the exit of the sector, until the initiation point.

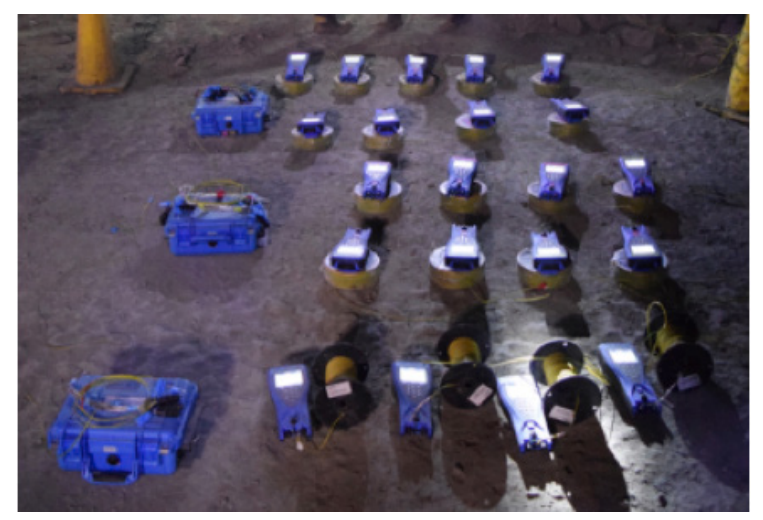

Figure 26 Installation Logger and Blaster300 in field

\subsection{Post-blasting}

\subsubsection{Geometry and fragmentation}

According to the information provided by the client, the mineral extraction lasted six to seven months after the blast, achieving the extraction of the 640,000 tons planned in the recovery.

The resulting fragmentation was adequate for continuous extraction, according to the client's production plan, as seen in Figure 27. 


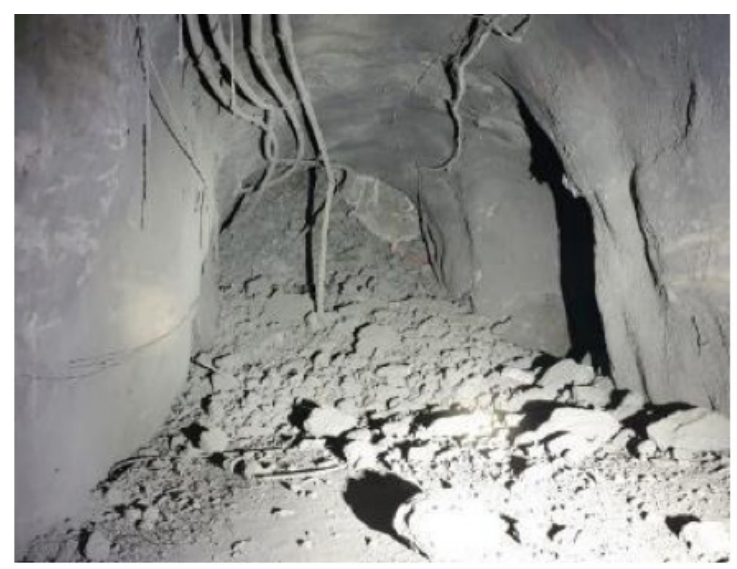

Figure 27 Fragmentation up level

The resultant geometry, to the current date, could not be measured. But according to the total extraction of the mineral, the scope of the geometry of the recovery zone can be assumed.

\subsubsection{Vibration}

At the measurement point close to the community (P2), vibration registered a value of $0.75 \mathrm{~mm} / \mathrm{s}$ to 1,500 meters and a frequency between 10 to $25 \mathrm{~Hz}$. In the measurement points in the underground mine, only one point registered a value of $21 \mathrm{~mm} / \mathrm{s}$ but at 200 meters from the blast. At this point, there was no visible damage, as shown in Table 5.

\section{Table 5 Blasting measured vibrations}

\begin{tabular}{|c|c|c|c|c|}
\hline Point & Distance & $\begin{array}{c}\text { Estimated } \\
\text { PPV (mm/s) }\end{array}$ & $\begin{array}{c}\text { Measured } \\
\text { PPV (mm/s) }\end{array}$ & Variation \\
\hline P1 & 250 & 20.6 & 21.6 & $+5 \%$ \\
\hline P2 & 2,000 & 1.1 & $<0.50$ & $-55 \%$ \\
\hline P3 & 1,500 & 1.6 & 0.75 & $-42 \%$ \\
\hline
\end{tabular}

\section{$3 \quad$ Results}

The totality of the ore of the rib, sill and crown pillars was recovered. This was checked according to the extracted tons and information indicated by the customer. This allowed production for seven months after the blast that corresponded to $30 \%$ of the annual production of the mine. The fragmentation resulting was adequate for continuous extraction according to the production plan.

The vibrations generated by the blast were lower than the estimated values according to the vibration predictive model. The maximum vibration in the nearby community was 0.75 millimeter per seconds and a frequency of 12 Hertz. This value, according to USBM \& Goldman criteria, is close to the perceptible range, but did not affect the community located 1,500 $\mathrm{m}$ from the blast. The explosive load operation lasted 32 continuous days without incidents during which time approximately 250 tons of explosives were loaded. The explosive type used was bulk emulsion (Subtek ${ }^{\mathrm{TM}}$ Velcro and Charge) and package emulsion.

In the blast 4,913 i-kon ${ }^{\mathrm{TM}}$ III electronic detonators were used and programmed successfully and blast length- time was 26 seconds. For registering and programming, 21 Loggers and five Blaster 3000s were used successfully. Originally a LAN communication system was planned, but finally plan B using a wire was implemented. 
According to Orica's records, this blast marked a global milestone as the largest in terms of number of electronic detonators in a trouble-free event (4,913 i-kon III TM detonators) and within the top 10 in terms of broken material.

\section{$4 \quad$ Conclusions}

The use of technology (explosives and detonators) and mechanization of the loading systems in the underground processes makes possible the blasting of large tonnage, reducing risks and improving safety and productivity.

Bulk emulsions allow the compressed air that is used with ANFO in up blastholes to be eliminated. Also, the technology improved field implementation, regarding the precise location of explosive charges and lengths of explosive columns. As for environmental issues, the use of bulk emulsions reduced the generation of waste such as bags, boxes and other materials.

The use of electronic detonators allowed increased flexibility of the timing sequence and a greater window of time. The precision allowed the explosives per delay to be managed to minimize the coupling of the waves. In addition in terms of safety, permanent control of the state of the detonators, even before the blasting process was also a plus.

Reducing the number of smaller blasts to instead create one mass blast allows the work cycles associated with the preparation of each blast, drilling recoveries, ventilation, safety and the processes previous to each small blast to be eliminated.

\section{Acknowledgements}

We wish to thank the client and their technical/operational teams for the trust given to execute this significant challenge. Also we would like to thank the client's Operational Leader who was able to manage, administer and bring together the different collaborating companies so that this task was carried out without on-site incidents/injuries. Thanks to all Orica staff involved in each stage of the process to achieve a successful mass blast.

\section{References}

Case Study Underground Mass Blast St Barbara Southern Cross, Marvel Loch, Australia.

Holmberg, R 1979, 'Design of Tunnel Perimeter Blast-hole Patterns to Prevent Rock Damage'.

JKTech 1998, 'JKSimblast - Blast simulation, evaluation and management. 2D Ring, Underground Blast Design', Queensland, Australia. 